Moving Beyond Goffman: The Performativity of Anonymity on SNS 
Title - Moving Beyond Goffman: The Performativity of Anonymity on SNS

Purpose - This paper explores consumer behaviour on the popular anonymous social networking site (SNS) Yik Yak. It examines the reasons behind the turn to anonymous social networking and also considers the ways in which anonymity impacts consumers' selfperformances on SNS.

Design/Methodology/Approach - The study utilised a netnographic approach to explore Yik Yak across eight universities in Ireland and the UK. Data are based on observation and participation on the app. Screenshots on smart phones were the central method used to collect data. Data also included twelve in-depth interviews.

Findings - Young consumers are becoming fatigued by the negative effects of selfpresentation on many SNS. By enabling consumers to engage in what they consider to be more authentic modes of being and interaction, Yik Yak provides respite from these pressures. Through the structures of its design, Yik Yak enables consumers to realise self-authentication in anonymised self-performances that engender a sense of virtue and social connection.

Originality/Value - By invoking a performative lens, this paper extends a novel theoretical approach to understandings of identity formation within consumer research. Highlighting anonymity as a dynamic process of socio-material enactments, the study reveals how consumers' self-performances are brought into effect through the citation of various discursive arrangements, which promulgate distinct understandings of authenticity.

Practical Implications: This research highlights the potential value of anonymous SNS in fostering supportive dialog, concerning mental health amongst post-millennials.

Keywords - Performativity, Anonymity, Facebook Fatigue, Authenticity, Netnography, Social Networking Sites (SNS)

Paper Type - Research Paper 


\section{Moving Beyond Goffman: The Performativity of Anonymity on}

\section{SNS}

\section{Introduction}

In the UK, $68 \%$ of adults view social media weekly, and this increases to $91 \%$ amongst the 1624 age category (Ofcom, 2016). Of these post millennials, 44\% access their social media profiles more than ten times per day, with over $70 \%$ logging on through smartphone applications (ibid). The success of social networking sites (SNS) brings with it a new emphasis on presenting and maintaining an identity online (Schau and Gilly, 2003; Belk, 2013; McQuarrie et al., 2013). Amongst post-millennials we identify an emerging phenomenon whereby consumers are increasingly turning to anonymous SNS. A recent Pew report (2013) indicates that $61 \%$ of consumers have recently taken a break from Facebook. The proliferation and success of anonymous applications such as Kik (300 million users) and Whisper (20 million users) highlights the significance of the turn to anonymous social networks. To explore both the behavioural and cultural impact of this emerging phenomenon we pose two research questions: (1) Why are young consumers turning to anonymous SNS? (2) In what ways does anonymity impact consumer behaviour on SNS? To address these questions, we examine Yik Yak, a popular anonymous platform used by students on university campuses to discuss a range of issues that include: campus life, sexuality, pop culture and race (see Black et al., 2016).

As a deeply relational concept (Scott and Orlikowski, 2014), anonymity provides a novel starting point for us to explore the ways in which consumers' identities come into being on SNS. Within consumer research, references to anonymity have, for the most part, been concerned with protecting the identities of research participants. Investigations of SNS, too, have exclusively focused on platforms where consumers' identities are known (Wilcox and 
Stephen, 2013; Anderson et al., 2016; Marder et al., 2016). Consumer researchers commonly draw upon Goffman's $(1959 ; 1961)$ theories of identity and social performance when examining digital self-presentations (Schau and Gilly, 2003; Belk, 2013; McQuarrie et al., 2013; Marder et al., 2016). This perspective is underpinned by distinct ontological assumptions regarding the nature of the self. Application of Goffman's social performance extends the belief that, beneath the surface of self-presentations, there resides a core-self which encompasses fundamental character traits and inner qualities that persist over time. This core-self is responsible for shaping the identity goals that consumers strategically pursue (Belk, 2013; Schau and Gilly, 2003). We will demonstrate that this focus is limited because it overemphasises the significance of consumers' self-reflections, whilst overlooking the discursive and material influences that shape consumers' reflections and actions. Seeking to redress this imbalance, we invoke Butler's $(1990 ; 1993)$ theory of performativity to turn attention to the processes through which anonymous, consuming subjectivities are brought into effect. Invoking performativity enables us to contextualise consumers' reflections and actions in relation to broader material and discursive influences (Thompson and Üstüner, 2015). This research contributes an alternative ontology for understanding consumer identity, while also explicating this approach to extend our understanding of anonymity in consumer research.

In the following sections, we first provide an overview of consumer research on digital selfpresentation, while also highlighting the influence of Goffman's theories of social performance in shaping these accounts. Second, we introduce Butler's $(1990 ; 1993)$ theory of performativity, emphasising important distinctions in relation to prior understandings of social performance in consumer research. Third, we conceptualise anonymity while also highlighting the applicability of performativity theory in terms of unpacking this construct. Fourth, we introduce Yik Yak as the research context. Fifth, we detail our netnographic approach and 
outline the research journey. Finally, we present our findings and develop contributions in relation to anonymity and identity formation on SNS.

\section{Consumer Research and Digital Self-Presentation}

Every day billions of consumers upload pictures and videos online; the subject matter of these outward displays can traverse from once-in-a-lifetime extraordinary experiences to the most mundane moments of daily life. Castells $(2007,240)$ defines this phenomenon as the age of mass self-communication, describing it as 'a new pattern of sociability based on networked individualism, and the desire for individual autonomy based on self-defined projects of life'. Across the social sciences a multitude of studies have investigated the proliferation of SNS; researchers have examined the impact of these technologies in terms of identity construction (Zhao et al., 2008; Marwick, 2015), social relations (Zywica and Danowski, 2008) and psychological well-being (Gonzales and Hancock, 2011; Feinstein et al., 2013). Within consumer research, attention has primarily focused on examining how SNS impact consumers' self-presentations (Belk, 2013; McQuarrie et al., 2013), in terms of self-definition (Murray, 2015) impression management strategies (Schau and Gilly, 2003; Pounders et al., 2016) and self-esteem (Wilcox and Stephen, 2013).

Consumer researchers have fruitfully worked with Goffman's theories $(1959,1961)$ of identity and social performance to make sense of consumers' digital self-presentation strategies (Schau and Gilly, 2003; Belk, 2013; McQuarrie et al., 2013; Berger, 2014; Marder et al., 2016). In particular, Goffman's (1959) dramaturgical metaphor has provided the basis to develop insights into consumers' identity expressions. This metaphor conceptualises everyday life as the stage upon which social performances are played out. Goffman separates social participants into actors and audiences; actors perform the part of their desired character, while audiences 
judge the performances of actors and evaluate the authenticity of their character. Front stage performance provides an opportunity for actors to give off, manage and maintain impressions with the audience. Goffman maintains that front-stage performances are inherently lacking in authenticity, while more authentic ways of being are invariably reserved for private spaces, which he refers to as the backstage.

McQuarrie et al. $(2013,140)$ describe blogging as the 'apotheosis of Goffman's dramaturgical metaphor'; bloggers are afforded with the capacities to develop personas far removed from any previous presentations of self. At times more akin to a dress rehearsal than a live performance, blogging enables consumers to display their tastes to large audiences of strangers, with the aspiration of accumulating cultural, social and financial capital (McQuarrie et al., 2013). In order to feign similarity with their audience, successful bloggers deploy self-deprecating language when describing their physical appearance, bad habits and embarrassing moments. This strategic manoeuvre enables bloggers to appear 'ordinary', giving the impression that their lifestyles are genuinely obtainable. These practices are indicative of the type of misrepresentation of social position evoked in Goffman's (1959) notion of front-stage performance.

Schau and Gilly's (2003) research utilises Goffman's (1959) concept of impression management to highlight key distinctions between consumers' digital self-presentation strategies and those exhibited in the real world. In virtual settings, the symbolic meanings associated with consumption choices takes on additional significance, as consumers carefully consider the symbolic values of objects, places, signs and symbols before establishing connections with the self. This process sees consumers 'engage in complex intraself negotiations to project a desired impression' (Schau and Gilly, 2003, 387). From this 
perspective, self-presentation relies upon the manipulation of signs in order to impart a sense of identity. For Berger (2014), consumers' self-expressions are shaped by the understanding that status can be achieved if audience impressions are managed effectively. In this respect, consumers signal their identities by strategically engaging in interactions that communicate their desired identities. In drawing upon this notion of impression management, Berger (2014) extends a Goffmanesque understanding of identity expression on SNS as an informed, strategic and calculative act.

Similarly, Belk (2013) builds upon Goffman's (1961) concept of identity kits, which are the possessions that people keep in order to feel safe in their self-identity and self-presentation. He argues that as a result of the multiplicity of their functionality, smart phones have become the essential object in consumers' identity kits. The inclusion of personal details, social connections, interests and histories of activity and interactions on SNS means that when we $\log$ in we are essentially, 'checking to see who we are, who we were, and who we seem to be becoming' (Belk, 2013, 492). Smart phones become essential to consumers' digital selfpresentations because they provide a mobile means of managing and maintaining the self.

A recent phenomenon emanating from the affordances provided by smartphones is the selfie. In producing this self-expressive style of contemporary photography (Lim 2016) consumers must develop visual literacy in relation to the relevant cultural codes and signs in order to comprehend and develop competencies in 'snapshot aesthetics' (Schroeder, 2013), a style of photography that involves capturing every-day experiences in a manner that depicts a sense of authenticity. Eagar and Dann (2016) unpack the ways in which consumers employ the selfie to create a human-brand self-narrative (Goffman, 1959). In dismantling the established image production structures, the selfie has led to the rise of the consumer as 'brand manager'. From 
this perspective, the selfie is conceptualised as an agentic construction, which is actively managed by individuals before its dissemination on SNS (Eagar and Dann 2016). Following a similar line of reasoning, Gannon and Prothero $(2016,1861)$ pose two questions in their research: 'are selfies always the product of narcissistic, attention seeking motivations, or are they used as an expression of true selves?' While acknowledging that the selfie provides additional degrees of consumer agency, we contend that digital self-presentations remain rooted in broader socio-cultural and socio-material structures that shape and constrain consumers' self-presentations. Cumulatively, these studies extend the Goffmanesque notion that beneath the surface of self-presentations, lies a core self that formulates the identity goals that orientate consumers' strategic actions (see Table 1). We argue that reflexive awareness of identity goals does not absolve consumers from the wider structures of power that regulate and impose censors on self-presentations (Thompson and Üstüner, 2015).

Driving the research agenda within consumer research has been the understandable concern to document the evolution of self-presentation within the age of mass self-communication. As a product of our culture, the technologies of mass self-communication emphasise individual autonomy and the project of self-construction (Castells, 2007). Invoking Goffman's theories of identity and social performance has justifiably led consumer researchers to position the reflexive subject at the centre of analysis of self-presentations on SNS. This framing has consequently sustained an ontology which conceives of the consuming subject as a pre-existing self that displays a conscious understanding of the audience and is equipped with the capability to manage impressions (Gregson and Rose, 2000; Cover, 2012). But, as a product of the culture of mass self-communication, these technologies emerge as an effect of the discourses, interests and power relations that govern the design of SNS technologies. This understanding highlights the pertinent need to examine the cultural influences that shape and constrain self-presentations which appear, at least on the surface level, to emerge as a result of consumers' conscious, 
reflexive and strategic actions. This reframing requires analytic frameworks that are capable of contextualising consumers' reflections in relation to the broader cultural influences that shape consumers' sense making activities and actions. The analytical reframing proposed in this paper, performativity, we demonstrate is well suited towards this end.

\section{Performativity}

Judith Butler's $(1990 ; 1993)$ influential work introduces alternative ideas about performativity and agency. Working from a post-structuralist, anti-foundationalist perspective, she frames identity as a continuous process of becoming as opposed to an ontological state of being (Cover, 2012). Crucially, from this ontological standpoint, the world and our being comes into effect through performativity. This performative ontology may seem counterintuitive when the empirical realities that we investigate appear as 'prior, single, independent and determinate' (Law, 2004: 137). However, Butler (1994) maintains that it is crucial to delineate the distinctions between performance and performativity, as the former presumes a subject while the latter contests the notion of a subject.

While Goffman's self-presentations emerge from a subject that is knowledgeable, conscious and aware of the audience, Butler theorises a subject who is 'opaque, unknown to itself, characterised by what she calls its "unbearable relationality" to the other' (Butler and Salih, 2004, 2). This subject is deeply connected to the other because it is dependent upon it for recognition. Butler's characterisation of the subject as opaque and unknown to itself depicts a theory of subject-formation that recognises the limitations of the self and self-knowledge, while emphasising the importance of the inter-subjective bonds that link people together. As actors in the world, consumers' performances are always culturally constituted: they 'cite' norms and act in ways that accord with their cultural experiences (Butler, 1990). For example, consumers 
may unconsciously cite normative scripts of masculinity when performing masculine identities. Essentially, the performative self comes into being through repetitive behaviours and actions. Accordingly, 'performativity must be understood not as a singular or deliberate 'act', but rather as the reiterative and citational practice by which discourse produces the effects it names' (Butler, 1993, 2). This reversal of cause and effect, in terms of understanding identity construction, thus indicates that a subject is produced through discourse: the subject is the effect of discourse as opposed to its cause (Salih, 2002). In this understanding a subject is often produced through 'interpellation' and 'foreclosure' (Butler and Salih, 2004; Butler, 1997); that is, the process by which individuals enact their subject position in relation to discourse, and the ways in which subject positions can inhibit certain behaviours.

For Butler, then, identity is brought into being in accordance with culturally constructed discourses, practices and structures. These elements have a stabilising impact upon the subject when they become embodied in thoughts, feelings and actions. It is at this point that the individual's performances appear to emerge from their identity as opposed to being constitutive of that identity. Furthermore, the discourses that consumers cite can be multiple and contradictory: yet they are always productive in terms of producing specific effects, which is where they become powerful. Discourses have the capacity to limit subjects as they bring them into effect (Gregson and Rose, 2000) but they can also be subject to a process of 'resignification' and ascribed new meanings (Butler, 1990). For example, resignifications can confront hegemonic gender norms and contest masculine-feminine binaries through irony, parody and subversion of habituated symbolic boundaries (Butler 1990; Thompson and Üstüner, 2015). Importantly, the Butlerian subject is neither fully determined by discourse nor completely free to fashion discourse at will (Salih, 2002). Subsequently, it can be can argued that 'performances of identity which may appear to be wilful and reflexive are acts which constitute the narrative 
of selfhood, retroactively establishing the subject who speaks' (Cover, 2012, 183). Essentially, the key distinction offered by the theory of performativity is that ways of being and doing are constitutive of the self as opposed to being representative of identity and selfhood. Although performances may create the illusion of a real or core self, Butler contends that the actors are an effect of these performances (Butler, 1990). Invoking performativity in this research will enable us to demonstrate that consumers' activities on SNS contribute to the performance and stabilisation of identity while at the same time contributing to identities that are more fragmented and conflicting. In doing so we unpack the discourses that inform citational performances in order to understand the terms through which consumers' identities come into effect. Performativity provides an avenue to question how the functionality of SNS structure self-performances, while also enabling us to conceptualise anonymity as a dynamic process of socio-material enactments.

\section{Anonymity}

Anonymity is essentially social: being anonymous requires the presence of others (see Marx, 1999). It is also closely linked to personal identity: it encompasses a person's capacity to be free from identification with their actions. Anonymity enables people to conceal or reveal information at their discretion; as a core aspect of informational privacy it is central to the capacity to control personal information. The proliferation of mass self-communication technologies has ensured that anonymity remains a source of contention amongst scholars. Some scholars regard it as a necessary tool to protect private information, freedom of expression, creativity, and personal expression (Brazier et al., 2004). Meanwhile, others argue that anonymity reduces personal responsibility and fosters environments conducive to hate speech and defamation (Levmore and Nussbaum, 2010). 
Marx (1999) contends that scholars of anonymity would be ill-served by latching on to either of these dichotomous viewpoints. He reminds us that scholarly understanding of technology, privacy and anonymity is still in its infancy. Like all aspects of technology, the effect of anonymity can only be evaluated in terms of what we do with it (Boellstorff, 2015). Because of its reliance on technology, anonymity on SNS must be understood as a dynamic process of socio-material enactments [1] (Scott and Orlikowski, 2014). Given that the performative approach is orientated towards examining practices that perform particular phenomena (Barad, 2003), the present study embraces anonymity as a dynamic process of becoming, turning attention to the socio-material characteristics of anonymity as it is brought into effect through performance. In conceptualising performativity as an effect of discursive and material power relations, Butler's framework provides an innovative means of conceptualising anonymity. The social dynamics of anonymity, are well matched to a Butlerian subject that is deeply connected to the other through its need for recognition.

\section{Yik Yak}

While anonymity is certainly not new to the internet, recently a host of anonymous SNS have come to occupy a significant space in the digital marketplace. Although anonymous networks have proven to be popular platforms with consumers, organisations have so far failed to effectively monetise their potential. For example, Yik Yak was launched in 2013 and almost immediately garnered a huge customer base, while also attracting more than $\$ 73$ million in venture capital (Carson, 2017). The app provided anonymous proximity-based posting, geolocating users and allowing them to post "a yak" - an anonymous 200-character message - to a localised cohort called a "herd". Yak's were designated an 'OP' symbol denoting the term 'Original Poster', with responses randomly assigned symbols based on a camping motif. Users were then afforded the ability to vote once, choosing to either up-vote, down-vote or not vote 
at all. Yaks which received five down votes were automatically deleted and removed from the application's feed.

In March 2016 the organisation implemented mandatory user profiles, embracing identitybased posting in an effort to monetize its offering. This strategy was met with huge criticism from its consumer base, to such an extent that the organisation reverted back to completely anonymised posting by November 2016. Despite once being valued at $\$ 400$ million (Carson, 2017), the organisation announced its closure in April 2017 as a result of its failure to monetize effectively. A host of copycat applications such as Spout, Yodel, Swiflie and Convertly have since occupied this space. Offering geo-location, user voting systems and similar user interfaces (see figure 1), these applications aspire to capitalise on the post-millennial appetite for anonymity.

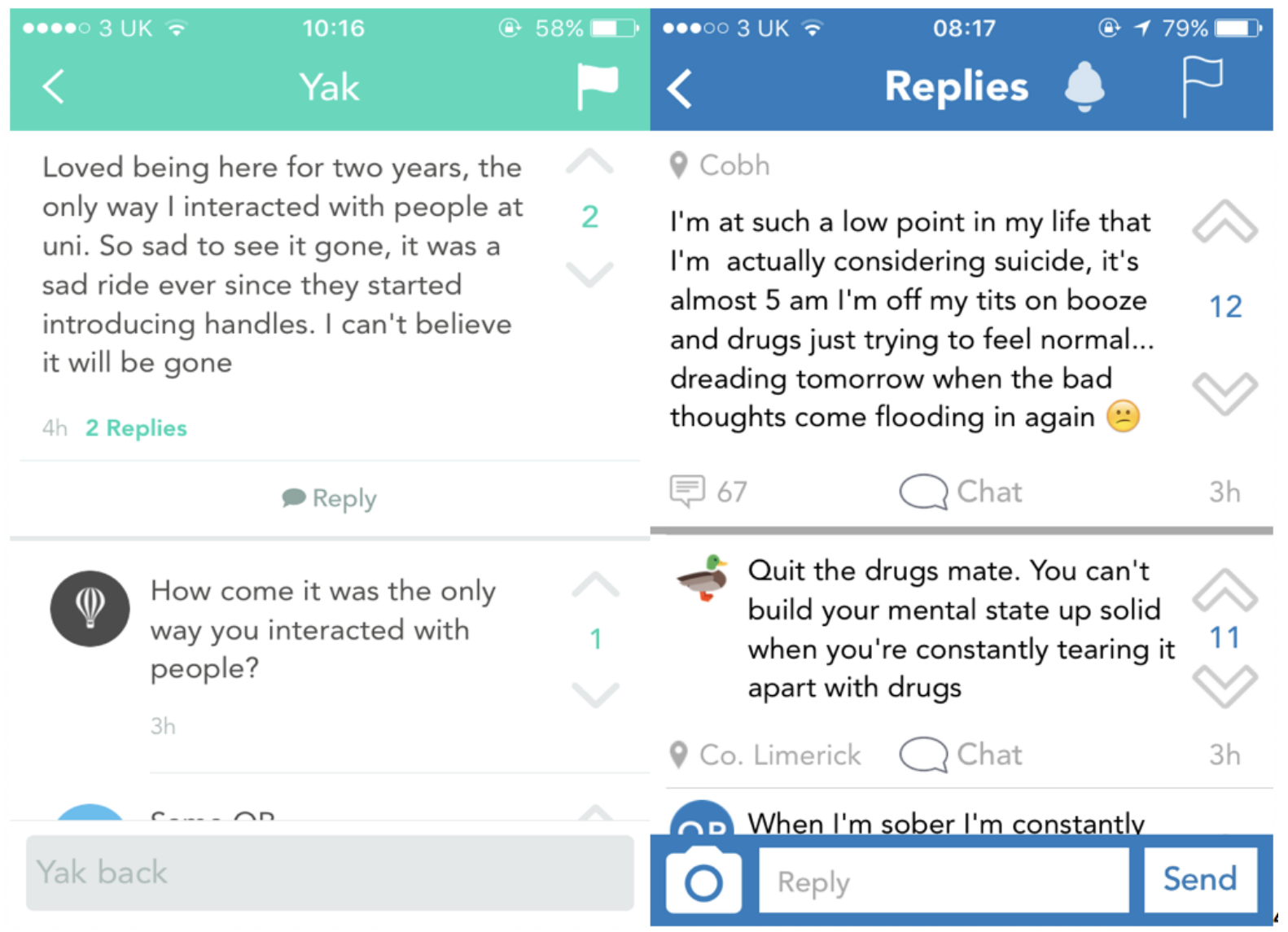

(Figure 1: Screen shot of the user interfaces on Yik Yak and Spout) 


\section{Research Methodology}

The findings of this study are based upon a combination of netnographic observation/participation and online text interviews (Kozinets, 2015). Netnography adapts ethnographic methods to examine online cultures and communities (Kozinets, 2002). It requires an immersive combination of participation and observation; we employed the following procedure for data collection and analysis.

Over a one-month period in June 2015, initial observations as non-participant observers were conducted across four "herds" in Ireland and the UK. This allowed us to gain cultural entrée to Yik Yak culture and develop familiarity with the workings of the app. Based on their highrates of participation and activity, we based our study on eight universities: Trinity College Dublin, National University of Ireland Galway, University of Limerick, University College Cork in Ireland and Oxford University, Lancaster University, Essex University and Edinburgh Napier University in the UK. Anonymity made it impossible for us to identify the exact demographics of the Yakkers that we observed; however, reports indicate that $99 \%$ of Yik Yak's user base is aged between 18-34 (Statista, 2016).

During the initial phase of observation we surveyed all interactions on the platform. Based on our observations, we employed a judgemental approach to sampling to actively select the most useful topics of interaction to address our research questions (Marshall, 1996). Based on their comparative prominence, we judged the topics of self-presentation, confession, advice-giving, provocation, illicit consumption and self-policing to be most useful for further analysis. Our second phase of observation commenced in December 2016. Over this three-month period, we used the screenshot function on our phones to record 4,231 images of anonymous interactions based on the selected topics. This data was organised by date and transferred to personal computers for coding and analysis. We employed Coffey and Atkinson's (1996) approach in order to organise the data into manageable categories. This process involved three stages: 1) 
recognising pertinent phenomena, 2) collecting examples of these phenomena, 3) establishing commonalities and differences across the data set. Through this iterative process of coding and interpretation, we identified preliminary themes and discussed possible linkages between them.

We began the second phase of immersive data collection by identifying ourselves as researchers and posing questions to the herds based on our initial themes. These interactions enabled us to develop rapport with the respondents, before inviting them to participate in more in-depth text interviews. In order to ensure that these interactions remained rooted in the consumption context we conducted these interviews through Yik Yak. In total, we conducted 12 interviews with participants spanning across each of the selected herds. We employed a semi-structured approach to interview design; first asking 'grand-tour' questions such as "can you tell me about Yik Yak?”, followed by 'mini-tour' questions (Spradley, 1979) which were asked to develop insights in relation to our emerging themes. Some participants responded quickly to our questions, which enabled us to complete the full interview in a few hours. Other participants responded less frequently, and in some cases interviews were drawn out over a number of weeks. The semi-structured interviews enabled us to further probe emic terms and member check interpretations (Kozinets, 2002). Further, the anonymised nature of these interviews assisted the participants in sharing their thoughts on subjects which may ordinarily be met with aversion in traditional face-to-face interviews (i.e., mental health, drug use, bullying, etc.). The combination of observation and participation enabled us to address the lack of contextual information resulting from the anonymised interview conditions.

In the final stage of analysis, we conducted axial coding to identify possible linkages between our open coding themes (Strauss and Corbin, 1990). At various stages throughout the process we repeated the iterative process of working across the data set to identify and refine our emerging themes. This informed a process of selective coding where previous themes were 
subsumed into three core themes for this study: idealised self-performances, toxic selfperformances and supportive self-performances [2].

\section{Data and Analysis}

Idealised self-performances - "Everyone on Facebook does it"

In the information age, SNS provide an important source of information in relation to young consumers' journeys of self-discovery and self-creation (Pempek et al., 2009). Yik Yak provides young consumers the opportunity to engage in what they consider to be more authentic modes of being and interaction:

Oars: Facebook is about how people pretend to live their life, Yik Yak is about how people actually live their lives.

Authenticity, as a discursive construction, emerges from a notion of selfhood which Sypher $(1964,15)$ defines as 'romantic individuality'. As a general preoccupation of contemporary consumer culture (Jacknis, 1990), authenticity is closely connected to consumers' concerns with accessing and revealing their 'true selves' (see Arnould and Price, 2000; Schouten and McAlexander, 1995). Brands continuously valorise authenticity, spinning stories about their own authenticity while also heralding it is an essential value of selfhood (Holt, 2002). Authenticity has thus become a powerful generative force, which is primarily manifested in the consumer's romanticised quest for authenticity (Beverland and Farrelly 2009). This discourse is particularly impactful in youth cultures, whereby claims to authenticity provide a means of establishing internal and external status hierarchies (Wheaton and Beal, 2003). Our participants regularly explained the differences between Facebook and Yik Yak with reference to the perceived authenticity of interactions on these platforms. For the participants Yik Yak 
interactions provide a stark contrast to the performances of idealised identities which are brought into effect on Facebook.

Tent: Nobody will dispute that people have become more sophisticated in terms of selfpresentation, but I think it's necessary to also recognise that our projected self-image is more fragile than ever before ... There's never been a time in history where our public veneer could be stripped away with a couple of clicks of a mouse ... I'm personally very controlling of photos of me, but I'm still featured looking far from my best on multiple public pages at festivals, events pubs and miscellaneous others ... There's just no way to avoid it anymore.

This excerpt is interesting because it situates these young consumers within the context of the age of mass self-communication (Castells, 2007). It also illustrates a concern common amongst our participants, relating to the pressures surrounding self-presentation on profile based SNS. Participants articulated a lucid understanding of the fragility of their identities and commonly expressed their fears and anxieties in relation to maintaining control of their identity performances on Facebook (Marder et al., 2016). The use of the term 'public veneer' is revealing as it suggests an external layer, or decorative cover, is applied over the real self, thus indicating recognition of the idealised nature of self-presentations on Facebook. This ideal is often predicated on celebrity discourse and the notion that consumers can themselves attain microcelebrity status on SNS (Senft, 2008). For Butler (1990), the self is constituted by a host of pre-given identity categories which, through repetitive citation, give rise to this illusion of a core self residing beneath the 'public veener'. Importantly, such repetitions are not doings by 'a subject who might be said to pre-exist the deed' (Butler, 1990, 25). However, the idealised self that appears to provide self-authentication on Facebook, remains a difficult prospect for 
most young consumers, particularly when we consider the extensive labour investment required:

Boat: Your Facebook friends may not be actively doing anything to seek attention, like regular status updates or photos, but having full control over their self-presentation is what I'm talking about ... Never before have we been able to completely control how other people see us and with social media we can. Your friends undoubtedly have their best pictures up of themselves for the best impression ... I'm not saying that in itself is a bad thing, everyone on Facebook does it. I did it myself when I first made Facebook because hey, that's what everyone else is doing right? ... You post an ideal version of yourself called the "hoped-for-possible self", an identity that isn't exactly the real you, but rather an identity you wish you were. On Yik Yak there's no pressure.

Boat illustrates how Facebook is orientated towards successfully negotiating a culture of reciprocal smiling and identity verification (Reed et al., 2012). Our participants were critical of the role of Facebook in terms of propagating this image-obsessed culture. Facebook's structures have a norm inducing effect which propels consumers to find and then present their 'best-self' (Zhao et al., 2008). The idealised-self becomes a construction to be consumed by others where interpellation (Butler, 1997) requires excessive maintenance (Gonzales and Hancock, 2011). Maintenance manifests in practices such as self-censoring (Das and Kramer, 2013), un-tagging unflattering photographs (Zywica and Danowski, 2008) and sharing affective and culturally relevant content (Anderson et al., 2016). Such idealised selfperformances, which are oftentimes at once unrealistic and unattainable, can invoke feelings of anxiety because of the weight of the expectations of living up to these ideals. 
OP: I can't stop comparing my life to other college students on Facebook. As in 'why can't I have as much fun as they have and why can't I have as many friends as them'. It really depresses me. I hate it.

Prior research demonstrates that social comparison on SNS can result in negative selfappraisal, which can lead to rumination and, in turn, depressive symptoms (Feinstein et al., 2013). Young consumers are continually forced to confront their self-image in order to create self-presentations, magnifying the view of others and ensuring that, even in the comfort of their own homes, they cannot escape the appraising gaze of peers. This can become problematic for young consumers as their 'social existence and self-concept may be inextricably bound to social networking' (Kedzior and Allen, 2016, 1899). In the competitive virtual campus, anonymity provides an alternative for those exhausted by the pressures of self-presentation and continuous social comparison, enabling a wider range of interactions which consumers consider to be more authentic.

\section{Toxic self-performances - "Fuck do I care if I offend anyone"}

According to Northcut $(2015,3)$, Yik Yak provides 'perhaps the greatest guarantee of anonymity combined with the least accountability ever seen on the social web' - under these circumstances interactions can become excessive and evolve into cyberbullying. A particular danger of Yik Yak is that it can be used as a vehicle to attack, defame or humiliate others (Black et al. 2016). For example, doxxing (Bancroft and Reid, 2017), the practice of revealing personal information the public, was prominent on the app: 
OP: $* * * * * *$ reported my picture of him, for those of you that didn't see it rest assured he's an ugly bastard, he's got a greasy ginger beard and a phat receding hairline.

Balloon: I saw it, then again I know him in real life and in person it's a lot worse.

Compass: His name is next to be posted if he carries on

Tent: Post it!!!! He’s a prick to everyone else.

Anonymity makes it easier to engage in these behaviours because feelings of sympathy are less likely to arise when the perpetrator does not know the identity of their victim (Whitaker and Kowalski, 2015). As illustrated above, some consumers use Yik Yak to 'abuse' others. Suler (2004) conceptualises this behaviour as part of the 'online disinhibition effect', where people express themselves more freely and feel less restrained in anonymous settings. The veil provided by anonymity allows consumers to engage in 'toxic disinhibition', where they are 'rude, critical, angry, hateful, and threatening' towards others (Suler, 2004, 1). On Yik Yak, toxic disinhibition commonly manifests in derogatory comments relating to issues of ethnicity, sex, sexuality and gender:

OP: Fucking Hate Travellers. What's not given to them for free they'll try rob.

OP: Women put their emotions before professionalism.

OP: Being gay is a mental illness.

OP: Male and Female are the only genders that exist. Your made up genders don't count. 
From these posts, it is clear that Yik Yak can become problematic when consumers find themselves toxically disinhibited as a result of the anonymity that the platform provides. As media reports on Yik Yak have widely publicised (Schuman, 2015; Mahler, 2015), anonymity can negatively impact behaviour when the fear of repercussion associated with offensive and derogatory posts is removed. Toxic disinhibition feeds into a process of deindividuation, where Yakkers tend to be 'less self-aware, engage less in self-evaluation and are less concerned about social comparison and evaluation ... which makes them feel less accountable for inappropriate online social behaviour' (Polder-Verkiel, 2012, 138). While some interactions on Yik Yak are clearly indicative of toxic disinhibition, our enquiry extends this understanding by demonstrating how these expressions are shaped through the invocation of cultural discourses:

OP: Brexit is an act of self-harm from a fundamentally depressed country

Mushroom: I'm not even playing anymore reactionaries everywhere are becoming so hateful and intolerant of any other opinion

Lantern: Brexit was an act of EXTREME PATRIOTISM in the face of the IMMIGRANT MENACE. DEUS VULT!

Mushroom: DON'T TRUST THE LUGENPRESSE

Lantern: YIK YAK IS FULL OF GLOBALIST SHILLS

The invocation of cultural discourses, was perhaps most apparent in the aftermath of political elections and referendums. As illustrated above, users employ a variety of rhetorical devices as a means of emotional appeal. The term Deus Vult, originally a battle cry of Christian crusaders, more recently appropriated by alternative right movements, is cited and resignified (Butler 1990) here by Lantern as a means of racial incitement. This language perpetuates an ideology of English nationalism, which was 'defined more by its fear of others (immigrants) 
than by a distinctive national sense of self' (Parry, 2016, np). Similarly, Mushroom elicits the term Lügenpresse (lying-press), a pejorative term originally used by German political movements to describe supposedly untrustworthy media. The term was recently resignified by alternative right movements to denounce all forms of media, that do not reflect their own worldview, as a 'hated Other' (Economist, 2017). Framing politics as a battle ground, this 'toxic discourse' (Parry, 2016) is part of an emerging 'febrile and instantaneous political culture that rewards those with the most uncompromising distaste for their opponents' (Bland, 2016). Within this context, Yik Yak provides a forum for fervent debate on issues such as freedom of speech, censorship, political correctness and the nature of offence:

Oars: I find a lot of "Western" people are so PC that they are anti-freedom of speech too

OP: I agree with Oars, a part of any liberal society is the right to criticise anything

OP: Safe places are bullshit. There are no safe places in the real world. The only safe place is in your home. GROW UP MILLENIALS ... Survival of the fittest. Pussies who get hurt over verbal encounters, maybe shouldn't survive lol

The issues raised in these posts are emblematic of a wider cultural debate, particularly prominent on university campuses, regarding freedom of speech and safe spaces. In negotiating this debate, these users draw upon an argument, first advanced in Willlis' (2014) book The Snowflake Effect, which bemoans post-millennials for their inflated sense of self-importance and psychological fragility. More recently the term has gained prominence, in both political and cultural discourses, with its meaning expanding as an epithet to use against 'anyone who could be accused of being too easily offended, too 
in need of "safe spaces", too fragile' (Goldstein, 2017). Although this epithet was originally levelled at the post-millennial generation, these users cite this discourse as a means of distancing themselves from their peers, or the fragile 'other' (Willis, 2014). Resignifying its meaning (Bulter, 1990), provides these users with the authority to claim that their viewpoint is representative of a reality that is "too real" for their peers to handle.

OP: right THAT'S IT I've cracked. PC culture has done me in. I'm left. I'm down for social equality and democracy and liberal values but the fuck do I care if I offend anyone anymore

Boat: It's just a fact that people can't speak freely and also not offend everyone...so if someone gets offended I usually view it as their problem.

These posts illustrate that some post-millennials have become disillusioned by what they experience as the restrictions enforced by PC discourses. Political correctness is concerned with establishing the cultural acceptance of diversity (Fairclough, 2003). For its proponents it encompasses a shift to alter cultural representations, values and identities, which is often pursued through attempts to change the discourse that people employ to speak about 'the other'. Anonymity enables consumers to circumvent this restriction, while embodying a view of authenticity that relates to their own perceptions regarding the purity of their motives. These consumers exhibit a belief in the virtue of speaking 'hard truths', believing this to be of greater societal value than protecting the fragile feelings of their 'easily offended' peers. The term social justice warrior (SJW) is regularly cited to label those who purportedly use offence as a basis to shut down non-pc forms of speech. Referred to as 'virtue signalling' in online parlance, users are 
charged with adopting superficial moral viewpoints for the purposes of enhancing their social standing. The citation (Butler 1990) of these ideological discourses invokes a toxicity, which ensures that these interactions invariably remain prone to contention.

\section{Supportive self-performances - "You're strong, you've been in this fight"}

Pejorative comments relating to race, gender, sexuality and ethnicity provoked many calls to ban Yik Yak (O'Dell, 2016). However, while these calls lament the negative impacts of anonymity, our findings demonstrate that consumers on Yik Yak were resourceful in terms of their capacity to manage and curtail the actions of the toxically disinhibited:

Balloon: The anonymity ensures that the bullies are the vast minority, people are much quicker to down vote a comment and stand up for others when they know they're anonymous.

Balloon's comment highlights consumers' capacities in terms of managing those that engage with Yik Yak for the purposes of demeaning others (Northcut, 2015). In terms of its architecture, Yik Yak is distinct from many other SNS; the voting function enables consumers to self-police from within the herd and thus develop its own standards from within the community. As Balloon highlights, anonymity is also empowering because it gives consumers the confidence to stand up for their beliefs. A strong culture of self-policing on Yik Yak ensured that cyber-bullies are kept in the minority. Through analysis, we begin to recognise that anonymity engenders a more complex range of behaviours than the toxic disinhibition widely reported by the media. It points us in the direction of the more benign side of online disinhibition which occurs when consumers 'reveal suppressed emotions, fears, and wishes' and engage in 'unusual acts of kindness and generosity, going out of their way to help others' 
(Suler, 2004, 1). Anonymity can create feelings of invisibility; very often, from behind the comfort of their screens, consumers 'talk freely about issues that could create inhibitions in a traditional face-to-face group, particularly when discussing sensitive topics' (Solomon, 1996, 9). This is true of Yik Yak:

Balloon: The relief of seeing that we are all a state! People post more real stuff here because it's anonymous. Nice change from other social media.

Boat: No one knows us here, it's like they say, telling a stranger about your problems is easier.

Hook: One of the positives of the anonymity is that people feel safe to open up about problems they're having. The advice that they get is almost very candid and helpful in most cases.

Once again the participants draw our attention to, what they consider to be, the more authentic nature of interactions fostered through Yik Yak. In this instance, authenticity is manifested in the feeling of social connection that emanates from their shared sense of vulnerability. According to Suler's (2004) online disinhibition effect, anonymity has a positive influence, when it provides a space for people to open up and express their thoughts and feelings. On Yik Yak, anonymity opens up space for discussion of a variety of stigmatising issues such as: depression; anxiety; self-esteem; self-harm; death and addiction. Anonymity enables young consumers to explore these issues without the fear of suffering reputational damage. Learning that other people share similar problems can positively affect consumers' well-being (Berger, 2014). For young consumers, these interactions may have provided their first opportunity to learn that other people are experiencing similar difficulties. 
OP: Currently struggling with suicidal thoughts and depression ... I think my housemates and friends are making it worse. Any advice for me UL?

Anchor: Forget the supposed friends we all have them chin up stick with the people that care about you

Fire: You should also go talk to a doctor OP

Map: OP you can get through this. You're strong, GO OPPPPP

Oars: Depression isn't always a temporary thing some people who are clinically depressed struggle with it their whole lives but there are always good days and you live for those days even if they are few ... and spread apart. You're strong, you've been in this fight and you wake everyday thinking you're going to beat it again today. Take it one day at a time make the battle smaller by taking it one step ... at a time. Get rid of the shitty friends you deserve better ignore your shitty housemates they aren't worth your time. Focus on yourself for a while find things that make you happy ... maybe even do something you always hoped to do but have been afraid to do it. But above all talk to someone whether it's a doctor a psychiatrist your parents or a trustworthy friend ... they're not going to look at you like you have three heads they'll be concerned and will help in any way possible even if it's just to listen. When life beats you down never give up keep fighting

OP: Thanks everyone I actually feel a bit better now

In our discussions with participants it became evident that they considered interactions involving confession and support as more authentic or real than typical interactions on other SNS. For these young consumers, a sense of authenticity emerges on Yik Yak through the sharing of personally sensitive information. In these instances, identities are performed in 
relational interactions that are supportive, sympathetic and empathetic in nature. These 'are performative acts of identification articulated through frameworks of relationality and belonging; specific activities which produce, constitute and stabalise the self' (Cover, 2012, 183). On first reading, these interactions are indeed representative of what Suler (2004) describes as benign inhibition. But with closer analysis, we started to view these confession/support interactions in a different light. In this interaction, the original poster provides a brief outline of their personal difficulties. After a series of brief motivational pitches from others, Oars attempts to motivate OP with a call to summon his or her internal strength in preparation for the 'fight'. In analysing the post's narrative construction, Oar's response reads more like a self-help column. But the excesses of this response lead us to question if it is more likely that Oars is actually working through his or her own difficulties by projecting these issues on to OP as 'the other'. In what Barthes $(1989,145-148)$ refers to as the effect of reality, there is a kind of banal excess in Oars' response, which leads us to question the significance of all the insignificant detail. Barthes argues that excess is significant in narrative construction because it creates a sense of 'concrete reality'. We argue that this narrative excess contributes to a sense of 'concrete reality', which creates the sense of authenticity that these young consumers are seeking. For interactions of this nature, this sense of authenticity relies upon the invocation of discourses of well-being in order to structure participants' supportive responses to vulnerable confessions:

OP: People who don't suffer from depression have no idea how hard the struggle of staying alive is when you constantly feel like just giving up

Boot: Not wanting to come off as ignorant but what is it that $u$ have to be depressed about and is there any proactive things $u$ can do to combat it? 
Tepee: Depression is a chemical imbalance in the brain boot. Sometimes it's not something your sad about in particular.

OP: You're right tepee, I'm not saying I'm going to go and top myself but I just feel so fed up of everything and people's ignorant comments like "snap out of it" don't help. Depression is real

Tepee: I haven't suffered from it myself but my ex had it really bad so I know a lot about it. It's horrible to deal with so can't imagine what it's like to have it. I'm here for you :) Acorn: It gets better. All you need is a positive mind-set. It's hard to get there but find something that makes you happy. When I was depressed I started working out and going on walks. Talk to more people. It really helped me! And I'm here to talk OP: Thanks tepee and acorn!

In this series of interactions, we see consumers using Yik Yak to interact around the very 'real' topic of depression. Anonymity is pivotal in shaping what comes to be viewed as authentic in these social interactions. Participants carefully police responses allowing little or no space for posts that they deem insensitive. Reprimands are common for those who do not adhere to this mode of interaction. Relationality is central to the performance of identity, the social surveillance exhibited in these interactions contributes to maintaince of social norms that govern social participation (Butler, 1990; 1993). We also see the responders drawing upon their personal experiences in order to give themselves credibility as they transition into the role of expert. With inadequate information about OP's predicament, Acorn offers prescriptive advice that appears to be derived more from his or her personal experience as opposed to a genuine understanding of OP's experiences. These authoritative self-performances enable selfauthentication on the part of the respondent. This is not a value judgement of these consumers but, rather, an analysis of the types of identity performances and subjectivities that Yik Yak 
brings into effect. We find that an affective sociality emerges through the performance of empathetic and supportive interactions which brings confessional and supportive and authoritative subjectivities into effect.

\section{Discussion}

\section{Insert Table 1 Here}

As illustrated in table 1, authenticity emerged as a recurring theme which was representative of the shared experiences of young consumers on Yik Yak. Beverland and Farrelly $(2009,839)$ note that 'authenticity is a socially constructed interpretation of the essence of what is observed rather than properties inherent in an object'. They contend that consumers are motivated to pursue identity goals that convey authenticity. Self-authentication is primarily driven by the desire to realise particular identity benefits (control, virtue, connection). Importantly, in conceptualising SNS as a space for such intelligible identity performances, we posit that consumers utilise these resources in a variety of ways and to varying degrees; 'and that at no stage is this necessarily a conscious, voluntary moment of identity construction but just as reiterative, hidden and disavowed as a masculine way of walking performs, stabilises and is consistent with a male identity' (Cover, 2012, 181). In this understanding, we now focus on

unpacking the various discursive resources that shape consumers' understandings of authenticity on SNS, in order to grasp the identity benefits that they pursue (Butler, 1990; 1993).

\section{Celebrity, self-reflexivity and idealised selves}

This paper posed two research questions. The first of which was to identify why young consumers are increasingly turning to anonymous SNS. We contend that post-millennial consumers are beginning to experience, what social media researchers describe as Facebook fatigue (Bright et al., 2015; Cramer et al., 2016). This became evident as participants relayed 
the weight of expectation that they experienced in maintaining idealised self-presentations on Facebook. Facebook and Yik Yak differ vastly in terms of how their structures shape identity performances. Through its architecture, Facebook promulgates a consumerist culture based upon conspicuous consumption, self-creation and taste displays. This idealised self is a commodity sign; it is an entity that engages in labour, while also simultaneously signalling to others the work that it is engaging in, always aiming to embody sought after cultural values (Hearn, 2008). In this way, Facebook encourages identity performances which stylistically and repetitively cite (Butler, 1990) the tropes of celebrity discourse (see Marwick, 2015).

This discourse is having a norm-inducing effect, creating a culture in which post-millennials are continually confronted by idealised self-presentations, subjected to appraising gazes and charged with administering reciprocal smiles. Young consumers are thus thrust into a position of forced reflexivity, as the process of profile creation requires them to observe, contemplate, label and articulate the self (Turkle, 2005). Facebook is having a destabilising effect upon the identities of many young consumers: in the process of creating these idealised selfpresentations, consumers' efforts serve to objectify the self and delimit its boundaries (Cramer et al., 2016). The unrelenting nature of this work has made post-millennial consumers' aware of the fragility of their identities. The participants illustrated concerns about maintaining control; they fear losing control and having their 'public veneer' stripped away. As a result, authenticity comes to be judged in terms of consumers' capacities to control their selfperformances in a manner that lives up to these expectations.

Beverland and Farrelly $(2009,841)$ assert that 'control is an end-state (whereby consumers seek to be "in control") rather than a process'. In combination, the structure of Facebook and the ever evolving nature of celebrity discourse ensures that consumers can never fully control 
this environment. Given the extensive labour required to even temporarily achieve control over one's self-performance (Anderson et al., 2016; Marwick, 2015), it is clear to see that young consumers are increasingly turning to anonymous SNS in an attempt to realise alternative identity benefits. Anonymity on Yik Yak removes users' capacities to accumulate reputational capital and thus alleviates the need to control self-performances to the same extent that is evidenced on profile based SNS. This provides a welcome and desired respite for young consumers amongst the pressures of idealised self-presentation. However, if consumers want to remain heard on Yik Yak, they must appreciate the social norms which shape interaction in order to avoid down-voting to the point of deletion. Through the structure of its design, Yik Yak enables alternative sets of identity performances.

\section{Battleground of toxicity}

Our data supports Suler's (2004) assertion that anonymity enables consumers to engage in toxic behaviours. In addressing our second research question, it is clear that anonymity provides a platform to voice contentious or even bigoted viewpoints, without fear of reprimand. Such behaviour may be motivated by desires to create alternative realities, with the intention of objectifying others in order to elevate one's own sense of self. Nussbaum $(2012,81)$ explains how the internet 'blurs the distinction between fantasy and reality, in that the objectifier's fantasy is out there, a piece of every reader's reality, and it also shapes reality'. These problems are not new to the internet, but the structure of Yik Yak's design makes it particularly problematic because it connects people within a clearly defined, localised social space. The practice of doxxing provides a pertinent example of how consumers, with malicious intent, may harm others in ways that can quickly seep from the virtual world. 
The absence of consequences on Yik Yak also engenders self-performances which invoke discourses on issues surrounding freedom of speech, safe spaces, censorship and offence. Such interactions frequently spark debate, with young consumers hotly contesting a host of divisive topics. Consumers frequently use their anonymity to reject the restrictions imposed by PC discourse. Given the current influence of these discourses in terms of shaping what consumers can and cannot say both on SNS (Bell, 2016) and university campuses (Lukianoff and Haidt, 2015), we argue that these interactions are significant in ways that extend beyond toxic disinhibition. Self-performances of this nature can be interpreted as indexically authentic, whereby the cues that guide self-expressions are believed to reflect a "true-self" (Grayson and Martinec, 2004). In these interactions, self-performances negate social convention providing a means through which users can resignify the meanings of discourses to express their authentic world view (Butler, 1990). In overriding considerations relating to the offence of others, Yik Yak supports self-performances that engender the identity benefit of virtuous selfauthentication. A sense of authenticity is realised in self-performances in which users vigorously express their moral fortitude. In these respects, toxic expressions on Yik Yak are significant in ways that extend beyond a perverse appetite for cyberbullying or defamation.

\section{Help-seekers and wounded healers}

The value inherent in these spaces of interaction is best exemplified in the benign behaviours exhibited on Yik Yak. Anonymity assists consumers in opening up, enabling them to express their vulnerability by sharing difficult experiences. As noted previously, we argue that these benign identity performances are shaped through the invocation of well-being discourses. As a cultural script, well-being invites a way of being that is deeply relational in nature. Nayar $(2011,4)$ contends that 'the relational monitor as emotionally meaningful discourse is essentially a discourse of transformation: it transforms the Self from an independent one into a 
relational one, and the Other from a distant, different Other into somebody essential for the Self's well-being'. We note similarities between Nayar's contention and the behaviour observed on Yik Yak: anonymity inspires identity performances that are deeply relational in nature, while also opening up possibilities for personal transformation.

With the removal of real life identities, benign identity performances become reliant upon an affective modality that sees social relations established through the sharing of emotions and experiences. By design, Yik Yak interactions are structured to be brief in nature and, as a result, the potential for limiting the distance (or truly getting to know) the other is always hampered. Yet consumers are frequently compelled to offer support because they themselves identify with the difficulties expressed by others. Responders slip in to the role of "wounded healer" (Jung, 1969), drawing from personal experiences in order to prescribe advice to support-seekers. These relations open up possibilities of personal transformation for both the care-giver and care-receiver.

By unpacking the narrative construction of these performances, we identified a tendency whereby consumers invoke the inspirational and motivational rhetoric of the self-help genre. This culture of well-being propagates the notion of the perfectible self that can be worked upon for self-improvement. Drawing upon personal experience and citing this influential discourse allows carers to elevate themselves to advise, prescribe, motivate and inspire, while still performing identities that are received as caring, supportive and empathetic in nature. In doing so self-authentication through projection of one's beliefs and past achievements can be achieved (Beverland and Farrelly, 2009). Anonymity thus opens up pathways to increase selfunderstanding and engage in self-development, to resolve interpersonal and intrapersonal conflicts and to explore emotional and experiential aspects of the self. The 'opaque, unknown' self and the relationality it relies on (Bulter and Salih, 2004) thus provides self-authentication 
for both the help-seeker and wounded healer via the sense of emotional connectedness that is shared in these interactions (Beverland and Farrelly, 2009). This process, akin to the psychodynamic notion of 'working through' or the humanistic notion of 'self-actualisation' (Suler, 2004), hence, facilities the identity benefit of personal enrichment through the fellowship of sharing with others, while lending itself to establishing anonymity as an authoritative performance (Arnould and Price, 2000).

\section{Theoretical Implications}

Based on the participants' reflections, it may be tempting to argue that the online disinhibition effect reveals intrinsic aspects of the consumer psyche, arguing that it allows repressed emotions and behaviours to come to the surface; to penetrate the guard of self-presentation, to reveal a more 'real self'. Similarly, Goffman's $(1959,1961)$ dramaturgical metaphor would have ushered us to highlight distinctions between the idealised front-stage performances of Facebook, while arguing that Yik Yak's backstage performances reveal a more 'true-self'. However, as a lens, performativity theory enabled us to see how consumer subjectivities are brought into effect on SNS (see Table 1). By situating this enquiry within the wider cultural practices of identity and self-hood, performativity enables us to extend the critical frameworks that consumer researchers employ to understand identity, while also destabalising the problematic dichotomy between 'real-life' and 'virtual' identities. In shifting the analytic focus away from the conscious actions of agentic consumers, we foregrounded the interrelations of discourses, practices and structures in the performance of identities. We demonstrated that the self consists of an array of pre-determined identity types and experiences, which are brought into effect through stylised, repetitive citation of discourse (Butler, 1990; 1993). On this basis, it became possible for us to demonstrate how SNS champion particular ways of presenting and categorising one's self while foreclosing others (Butler and Salih, 2004). We illustrated a variety of ways in which consumers act on Yik Yak, demonstrating the impact of these actions 
upon the self and others. This is not to say that consumers are sovereign subjects but instead it reminds how identities are in a constant state of becoming, sometimes occupying a number of subject positions and drawing upon a variant of resources and discourses to construct the self (Brickell 2003).

This understanding afforded us the opportunity to move beyond the reasons why consumers consume variants of SNS, to demonstrate how the socio-materiality of SNS come to shape enduring, consuming subjectivities (Scott and Orlikowski, 2014). We have illustrated how the design decisions made by platform creators both encourage and constrain particularised identity performances. This research extends understanding of identity expression on SNS by demonstrating how, 'in a very real sense, those who design new technologies are, by the very same stroke, designing society' (Lohan and Faulkner, 2004, 322). From this perspective, the consuming subject consists of compartmentalised selves that come into effect in the coming together of environments and discourse. The idealised-self performed on Facebook is part of the same self that defames others or expresses fears and anxieties on Yik Yak. We argue that consumers' affirmations about the self are invariably shaped by the traits and characteristics that society (and online communities) chooses to value. While this position may seem obvious, it represents a significant departure from the predominant valorisation of Goffman's consciously performing subject in consumer research. We maintain that selves are constituted in discourse but are also unconsciously reconstituted in the encounter with different new imaginative discursive arrangements (Butler, 1991; Cover, 2012). In the case of postmillennials, anonymity provides reprieve from the interpellation of celebrity discourse on identity based platforms whilst simultaneously facilitating a forum for resignification of meanings. Essentially, this study contributes to our understanding of identity on SNS by demonstrating that consumers' ways of being and doing are constitutive of the self rather than 
representative of identity and selfhood. While these performances create the illusion of a real self, the identities of these consumers are an effect of performance.

Resisting the temptation to adopt a binary conceptualisation of authenticity, this enquiry also further develops understandings of authenticity as a socially constructed concept. In highlighting the dual role of discourse and SNS design, the present study demonstrates the influence of socio-material relations in shaping varying manifestations of authenticity on SNS. By encouraging the citation of celebrity tropes through idealised self-performances and continuous self-maintenance, Facebook promulgates a view of authenticity which necessitates that consumers must attain control over their self-performances to achieve self-authentication. On Yik Yak anonymity displaces this need for control, opening up pathways for consumers to, instead, realise self-authentication through contentiously virtuous and connection-seeking selfperformances (Beverland and Farrelly, 2009). These socio-material factors are influential in constructing and shaping what comes to be perceived as authentic on SNS. Butler $(1990 ; 1993)$ enables us to see that all forms of identity expression are constructed, although some are viewed as more authentic than others; what is really happening here is the 'circulation and privileging of particular imaginary authenticities' (Brickell, 2003, 169). On this basis, Butler $(1990,22)$ conceives of the self as an illusion of the problematic 'authentic-expressive paradigm'. As a social construct, we demonstrate that idiosyncratic understandings of authenticity emerge as an effect of the discourses that consumers observe on SNS.

\section{Practical Implications and Future Research}

Public health research illustrates that anonymity enables distinct modes of interaction, which makes anonymous networks a powerful tool for promoting health education and fostering dialogue around sensitive health issues (Beard et al., 2009). In the UK, one in four students are currently suffering from mental health problems (Aronin and Smith, 2016). These stark 
statistics place a responsibility on third-level institutions to effectively manage mental health. This research highlights the untapped potential inherent in anonymous SNS. We recommend that support services leverage this potential by placing trained support staff on anonymous SNS, with the aim of facilitating discussion, offering informed advice and directing young people to further support (for example of same see Big White Wall).

In unpacking the behaviour and cultural impact of anonymous social networking as an emerging consumption phenomenon, this study provides insight into the prevalent desire for anonymity in the digital marketplace. Anonymous SNS have the potential to be a disruptive force within a space that is currently dominated by profile-based SNS. As of yet, organisations have struggled to devise ways of effectively monetising anonymous consumer bases. As an avenue for future research, we recommend that market-researchers examine this space to ascertain the feasibility of anonymous SNS in terms of revenue generation. We also highlight the relatively untapped potential of Butler's theory of performativity in terms of extending understanding of self-performances in other contexts. As demonstrated in this paper, the performative ontology can contribute new and alternative understandings of consumer identity projects.

\section{Notes}

[1] Sociomateriality understanding aims to ground the ways in which technologies and their architectures create, sustain or change consumer subjectivities through a relational ontology between practices and materiality (see Scott and Orlikowski, 2014).

[2] For the purposes of presentation in this paper, some data excerpts are comprised of a series of yaks made by one user. Separate yaks are denoted by '...' to indicate where one ends and another starts. 


\section{Bibliography}

Anderson, S., Hamilton, K. and Tonner, A., (2016), "Social labour: Exploring work in consumption", Marketing Theory, doi: 1470593116640598.

Aronin, S., and Smith, M., (2016), "One in four students suffer from mental health problems", YouGov UK, available at: https://yougov.co.uk/news/2016/08/09/quarter-britain s-studentsare-afflicted-mental-hea/ (accessed 20th June 2017).

Arnould, E.J. and Price, L.L., (2000), “Authenticating acts and authoritative performances: Questing for self and community", in Ratneshwar, S., Mick, D.G. and Huffman, C. (Eds), The why of consumption: Contemporary perspectives on consumer motives, goals and desires, Routledge: London, pp.140-163.

Bancroft, A. and Scott Reid, P., (2017), "Challenging the techno-politics of anonymity: the case of cryptomarket users", Information, Communication \& Society, Vol. 20 No. 4, pp.497512.

Barad, K., (2003), "Posthumanist Performativity: Toward an Understanding of How Matter Comes to Matter", Signs: Journal of women in culture and society, Vol. 28 No. 3, pp.801-831.

Barthes, R., (1989), The Rustle of Language, trans. Howard, R., University of California Press: California.

Beard, L., Wilson, K., Morra, D. and Keelan, J., (2009), “A survey of health-related activities on second life", Journal of Medical Internet Research, Vol. 11 No. 2, doi: 10.2196/jmir.1192. Bell, E., (2016), “Twitter tackles the free speech conundrum”, The Guardian, available at: https://www.theguardian.com/media/2016/jan/10/twitter-free-speech-rules-hostile-behaviour (accessed 26th June 2017). 
Belk, R.W., (2013), "Extended self in a digital world”, Journal of Consumer Research, Vol. 40 No. 3, pp.477-500.

Berger, J., (2014), "Word of mouth and interpersonal communication: A review and directions for future research", Journal of Consumer Psychology, Vol. 24 No. 4, pp.586-607.

Beverland, M.B. and Farrelly, F.J., (2009), "The quest for authenticity in consumption: Consumers' purposive choice of authentic cues to shape experienced outcomes", Journal of Consumer Research, Vol. 36 No. 5, pp.838-856.

Black, E.W., Mezzina, K. and Thompson, L.A., (2016), "Anonymous social mediaUnderstanding the content and context of Yik Yak", Computers in Human Behavior, Vol. 57, pp.17-22.

Bland, A., (2016), "How did the language of politics get so toxic?”, The Guardian, available at: https://www.theguardian.com/politics/2016/jul/31/how-did-the-language-of-politics-getso-toxic (accessed 26th June 2017).

Boellstorff, T., (2015), Coming of age in Second Life: An anthropologist explores the virtually human, Princeton University Press: Princeton.

Brazier, F., Oskamp, A., Prins, C., Schellekens, M. and Wijngaards, N., (2004), “Anonymity and software agents: an interdisciplinary challenge", Artificial Intelligence and Law, Vol. 12 No. 1/2, pp.137-157.

Brickell, C., (2003), "Performativity or performance? Clarifications in the sociology of gender”, New Zealand Sociology, Vol. 18 No. 2, pp.158-178.

Bright, L.F., Kleiser, S.B. and Grau, S.L., (2015), “Too much Facebook? An exploratory examination of social media fatigue", Computers in Human Behavior, Vol. 44, pp.148-155. 
Butler, J., (1993), Bodies that matter: On the discursive limits of sex, Routledge: New York.

Butler, J., (1997), Excitable Speech a Politics of the Performative, Routledge: New York.

Butler, J., (1990), Gender trouble, feminism and the subversion of identity, Routledge: New York.

Butler, J., (1994), “Interview by Peter Osborne and Lynne Segal”, London, 1993.

Butler, J. and Salih, S., (2004), The Judith Butler Reader, John Wiley: New Jersey.

Carson, B., (2017), "The Yik Yak app is finally dead", Business Insider, available at: http://uk.businessinsider.com/yik-yak-shuts-down-2017-4 (accessed $6^{\text {th }}$ June 2017)

Castells, M., (2007), "Communication, power and counter-power in the network society", International Journal of Communication, Vol. 1 No. 1, pp.238-266.

Coffey, A. and Atkinson, P., (1996), Making Sense of Qualitative Data: Complementary Research Strategies, Sage Publications, Inc.: USA.

Cover, R., (2012), "Performing and undoing identity online: Social networking, identity theories and the incompatibility of online profiles and friendship regimes", Convergence: The International Journal of Research into New Media Technologies, Vol. 18 No. 2, pp.177-193.

Cramer, E.M., Song, H. and Drent, A.M., (2016), "Social comparison on Facebook: Motivation, affective consequences, self-esteem, and Facebook fatigue". Computers in Human Behavior, Vol. 64, pp.739-746.

Das, S., and Kramer, A. (2013), "Self-censorship on Facebook", In Proceedings of ICWSM, Cambridge, Massachusetts, pp.120-127. 
Eagar, T., and Dann, S., (2016), "Classifying the narrated \#selfie: genre typing humanbranding activity”, European Journal of Marketing, Vol. 50 No. 9/10, pp.1835-1857.

Economist, (2017), “America's alt-right learns to speak Nazi: "Lügenpresse"”, The Economist, available at: https://www.economist.com/news/europe/21710866-1848-1939-historypernicious-word-americas-alt-right-learns-speak-nazi (accessed 26th June 2017).

Fairclough, N., (2003), "Political correctness': The politics of culture and language”, Discourse \& Society, Vol. 14 No. 1, pp.17-28.

Feinstein, B.A., Hershenberg, R., Bhatia, V., Latack, J.A., Meuwly, N. and Davila, J., (2013), "Negative social comparison on Facebook and depressive symptoms: Rumination as a mechanism”, Psychology of Popular Media Culture, Vol. 2 No.3, p.161-170.

Gannon, V. and Prothero, A., (2016), "Beauty blogger selfies as authenticating practices", European Journal of Marketing, Vol. 50 No. 9/10, pp.1858-1878.

Goffman, E., (1961), Asylums: essays on the social situation of mental patients and other inmates, Basic Books: New York.

Goffman, E., (1959), The Presentation of Self in Everyday Life, Doubleday: New York.

Goldstein, J. (2017), “The surprising history of 'snowflake' as a political insult”, Think Progress, available at: https://thinkprogress.org/all-the-special-snowflakes-aaf1a922f37b (accessed 26th June 2017)

Gonzales, A.L. and Hancock, J.T., (2011), "Mirror, mirror on my Facebook wall: Effects of exposure to Facebook on self-esteem”, Cyberpsychology, Behavior, and Social Networking, Vol. 14 No. 1/2, pp.79-83. 
Grayson, K. and Martinec, R., (2004), “Consumer perceptions of iconicity and indexicality and their influence on assessments of authentic market offerings", Journal of Consumer Research, Vol. 31 No. 2, pp.296-312.

Gregson, N. and Rose, G., (2000), “Taking Butler elsewhere: performativities, spatialities and subjectivities", Environment and Planning D: Society and Space, Vol. 18 No. 4, pp.433-452.

Hearn, A., (2008), “Meat, Mask, Burden Probing the contours of the brandedself". Journal of Consumer Culture, Vol. 8 No. 2, pp.197-217.

Holt, D. B., (2002), "Why do brands cause trouble? A dialectical theory of consumer culture and branding", Journal of Consumer Research, Vol 29. No. 1, pp.70-90.

Jacknis, I., (1990), “Authenticity and the Mungo Martin House, Victoria, B.C.: Visual and Verbal Sources", Arctic Anthropology, Vol. 27 No. 2, 1-12.

Jung, C.G. (1969), Archetypes and the Collective Unconscious Collected Works of C.G. Jung, Volume 9 (Part 1), Princeton, N.J.: Princeton University Press.

Kedzior, R., and Allen, D.E., (2016), "From liberation to control: understanding the selfie experience", European Journal of Marketing, Vol. 50 No. 9/10, pp.1893-1902.

Kozinets, R.V., (2015), Netnography, John Wiley \& Sons, Inc.: New York.

Kozinets, R.V., (2002), “The field behind the screen: Using netnography for marketing research in online communities", Journal of Marketing Research, Vol. 39 No. 1, pp.61-72. Law, J., (2004), After Method: Mess in Social Science Research, Routledge: New York. 
Levmore, S. and Nussbaum, M.C., (2010), The Offensive Internet, Harvard University Press: Harvard.

Lim, W.M. (2016), "Understanding the selfie phenomenon: current insights and future research directions", European Journal of Marketing, Vol. 50 No. 9/10, pp.1773-1788.

Lohan, M. and Faulkner, W., (2004), "Masculinities and technologies: Some introductory remarks", Men and Masculinities, Vol. 6 No. 4, pp.319-329.

Lukianoff, G. and Haidt, J., (2015), "The Coddling of the American Mind", The Atlantic, available at: http://www.theatlantic.com/magazine/archive/2015/09/the-coddling-of-theamerican-mind/399356/ (accessed 12th October 2016).

Mahler, J., (2015). "Who spewed that abuse? Anonymous Yik Yak app isn't telling”, New York Times, available at: http://www.nytimes.com/2015/03/09/technology/popular-yik-yak-appconfers-anonymity-and-delivers-abuse.html?_r=0 (accessed 17th September 2016).

Marder, B., Joinson, A., Shankar, A. and Houghton, D., (2016), “The extended 'chilling' effect of Facebook: The cold reality of ubiquitous social networking", Computers in Human Behavior, Vol. 60, pp.582-592.

Marshall, M.N., (1996), “Sampling for qualitative research”. Family practice, 13(6), pp.522526.

Marwick, A.E., (2015), "Instafame: Luxury selfies in the attention economy", Public Culture, Vol. 27 No. 175, pp.137-160.

Marx, G.T., (1999), "What's in a Name? Some Reflections on the Sociology of Anonymity", The Information Society, Vol. 15 No. 2, pp.99-112. 
McQuarrie, E.F., Miller, J. and Phillips, B.J., (2013), "The megaphone effect: Taste and audience in fashion blogging", Journal of Consumer Research, Vol. 40 No. 1, pp.136-158.

Murray, D.C., (2015), "Notes to self: the visual culture of selfies in the age of social media”, Consumption Markets \& Culture, Vol. 18 No. 6, pp.490-516.

Nayar, P.K., (2011) "Cultures of Self-help, the Transformational Citizen and New Civic Order", available at: www.academia.edu (accessed 10th October 2016).

Northcut, K.M., (2015), "Dark side or insight? Yik Yak and culture on campus" In IEEE International Professional Communication Conference (IPCC), pp. 1-5.

Nussbaum, M., (2012), "Objectification and Internet Misogyny" in Nussbaum, M., and Levmore, S. (Eds), The Offensive Internet: Speech, Privacy and Reputation, Harvard University Press: Harvard.

O'Dell, L. (2016), "Freedom of speech concerns as university blocks Yik Yak", THE LINC, available at: http://thelinc.co.uk/2016/02/freedom-of-speech-concerns-as-university-blocksyik-yak/ (accessed 20th September 2016).

Ofcom, (2016), “Adults' media use and attitudes”, available at: https://www.ofcom.org.uk/_data/assets/pdf_file/0026/80828/2016-adults-media-use-andattitudes.pdf?lang=uqovrjuc (accessed 9 September 2016).

Parry, K., (2016), "The toxicity of discourse: reflections on UK political culture following the EU Referendum", EU Referendum Analysis 2016, available at: http://www.referendumanalysis.eu/eu-referendum-analysis-2016/section-5-campaign-andpolitical-communication/the-toxicity-of-discourse-reflections-on-uk-political-culturefollowing-the-eu-referendum/ (accessed 26 ${ }^{\text {th }}$ June 2017) 
Pempek, T.A., Yermolayeva, Y.A. and Calvert, S.L., (2009), “College students' social networking experiences on Facebook", Journal of Applied Developmental Psychology, Vol. 30 No. 3, pp.227-238.

Pew Research Centre., (2013), "Social media update 2013”, available at: http://www.pewinternet.org/2013/12/30/social-media-update-2013/ (accessed 1 June 2016).

Polder-Verkiel, S.E., (2012), “Online responsibility: Bad samaritanism and the influence of internet mediation", Science and Engineering Ethics, Vol. 18 No.1, pp.117-141.

Pounders, K., Kowalczyk, C.M., and Stowers, K., (2016), "Insight into the motivation of selfie postings: impression management and self-esteem", European Journal of Marketing, Vol. 50 No. 9/10, pp.1879-1892.

Reed, A., Forehand, M. R., Puntoni, S., and Warlop, L., (2012), "Identity-based consumer behaviour", International Journal of Research in Marketing, Vol. 29 No. 4, pp.310-321.

Salih, S., (2002), Judith Butler, Routledge: London.

Schau, H.J. and Gilly, M.C., (2003), "We are what we post? Self-presentation in personal web space”, Journal of Consumer Research, Vol. 30 No. 3, pp.385-404.

Schouten, J. W. and McAlexander, J. H., (1995), "Subcultures of consumption: An ethnography of the new bikers", Journal of Consumer Research, Vol. 22 No. 1, pp.43-61.

Schroeder, J. E., (2013), "Snapshot aesthetics and the strategic imagination”, Invisible Culture, Vol. 18. 
Schuman, R., (2015), "It's Not About Yik Yak", Slate, available at: http://www.slate.com/articles/life/education/2015/10/yik_yak_enables_bullying_and_hate_sp eech_but_banning_it_solves_nothing.html (accessed 10 July 2016).

Scott, S. V., and Orlikowski, W. J. (2014), “Entanglements in Practice: Performing Anonymity Through Social Media,” MIS Quarterly, Vol. 38 No. 3, pp.863-893.

Senft, T.M., (2008), Camgirls: Celebrity and community in the age of social networks, Peter Lang: New York.

Solomon, M.B., (1996), “Targeting trendsetters”, Marketing Research, Vol. 8 No. 2, pp.9-11.

Sypher, W. (1964), Loss of Self in Modern Literature and Art, Vintage: New York.

Spradley, J. P., (1979), The ethnographic interview, Holt, Rinehart and Winston: Orlando.

Statista, (2016), “US Millennial app usage concentration”, available at: https://www.statista.com/statistics/470730/millennials-app-user-concentration/ (accessed 2 November 2016).

Straus, A. and Corbin, J., (1990), Basics of qualitative research: Grounded theory procedures and techniques, Sage Publications, Inc.: USA.

Suler, J., (2004), “The online disinhibition effect”, Cyberpsychology \& Behavior, Vol. 7 No. 3, pp.321-326.

Thompson, C. J., and Üstüner, T., (2015), "Women skating on the edge: Marketplace performances as ideological edgework", Journal of Consumer Research, Vol. 42 No. 2, pp.235-265. 
Turkle, S., (2005), The second self: Computers and the human spirit, MIT Press: Massachusetts.

Wheaton, B. and Beal, B., (2003), “'Keeping It Real' Subcultural Media and the Discourses of Authenticity in Alternative Sport”, International Review for the Sociology of Sport, Vol. 38 No. 2, pp.155-176.

Whittaker, E. and Kowalski, R.M., (2015), "Cyberbullying via social media", Journal of School Violence, Vol. 14 No. 1, pp.11-29.

Wilcox, K. and Stephen, A.T., (2013), “Are close friends the enemy? Online social networks, self-esteem, and self-control”, Journal of Consumer Research, Vol. 40 No. 1, pp.90-103.

Willlis, T. (2014), The Snowflake Effect, Createspace: UK.

Zhao, S., Grasmuck, S. and Martin, J., (2008), "Identity construction on Facebook: Digital empowerment in anchored relationships", Computers in Human Behavior, Vol. 25 No. 5, pp.1816-1836.

Zywica, J. and Danowski, J., (2008), “The faces of Facebookers: Investigating social enhancement and social compensation hypotheses; predicting Facebook ${ }^{\mathrm{TM}}$ and offline popularity from sociability and self-esteem, and mapping the meanings of popularity with semantic networks", Journal of Computer-Mediated Communication, Vol. 14 No. 1, pp.1-34. 


\section{Table 1}

\section{'Goffman-esque' analysis of identity, authenticity and anonymity on SNS}

Identity on SNS

Authenticity on SNS

Anonymity on SNS

Identity on

SNS

Authenticity on SNS

Anonymity on SNS

Dramaturgy: SNS as a stage which affords consumers the capacity to develop personas far removed from any previous representation of the self (McQuarrie et al. 2013).

Impression Management: Consumers carefully consider the symbolic values of objects, places, signs and symbols to selectively create idealised self-presentations (Berger, 2014; Schau and Gilly, 2003).

Identity Kits: SNS technologies have become a fundamental basis through which consumers construct self- identity (Belk, 2013; Eagar and Dann, 2016).

Front and Back Stage Performances: Profile based SNS provide the stage for consumers' idealised self-performances. While consumers attempt to display a desirable character, audiences evaluate the authenticity of these portrayals (Kerrigan and Hart, 2016; Berger, 2014; Gannon and Prothero, 2016). Authenticity is often-times framed as a binary between authentic and inauthentic self-presentations (Wilcox and Stephens, 2013; Marder et al. 2016).

A Goffmanesque analysis of anonymity on Yik Yak: would have highlighted distinctions between the idealised frontstage performances of profile based SNS, while arguing that Yik Yak's backstage performances reveal a more "true-self".

\section{'Butler-ian' analysis of identity, authenticity and anonymity on SNS}

Identity performances: As actors in the world, consumers' performances on SNS are always culturally constituted: they 'cite' norms and act in ways that are shaped by the socio-material structures of SNS.

C Celebrity discourse: Profile based SNS such as Facebook encourage identity performances which stylistically and repetitively cite the tropes of celebrity discourse.

$>\quad$ Toxic discourse: Yik Yak facilitates the citation and resignification of a host of ideologically charged discourses relating to race, gender, ethnicity and sexuality.

* Well-being discourse: Similarly, on Yik Yak the cultural script of well-being invites a way of being that is deeply relational in nature.

Performativity accounts for how: the citation of these discursive arrangements, in conjunction with the socio-material structures of SNS, brings particular subjectivities into effect i.e. the idealised self-performance which is continuously subjected to the appraising gaze of others, and also charged with administering reciprocal smiles.

Authenticity as discourse: emerges from a romanticised notion of individuality. It is closely connected to concerns with accessing and revealing the "true-self".

Authenticity as Control: authenticity comes to be judged in terms of consumers' capacities to control their selfperformances in a manner that lives up to the expectations of celebrity discourse.

$>\quad$ Authenticity as Virtue: overriding considerations relating to offence, Yik Yak supports self-performances that engender the identity benefit of virtuous self-authentication.

* Authenticity as Connection: emerges through the sharing of personally sensitive information. In these instances, identities are performed in relational interactions that are supportive, sympathetic and empathetic in nature.

Performativity accounts for how: various socially constructed manifestations of authenticity come into effect in the interrelations between consumer actions and the socio-material structures of SNS.

Anonymity on SNS: must be understood as a dynamic process of socio-material enactments.

O Anonymity removes: users' capacities to accumulate reputational capital, thus alleviating the need to control self-performances to the same extent that is evidenced on profile based SNS.

$>$ Anonymity sparks: hotly contested debates concerning a host of divisive topics surrounding freedom of speech, safe spaces, censorship and offence.

* Anonymity enables: consumers to express their vulnerability by sharing difficult experiences, inspiring identity performances that are deeply relational in nature, while also opening up possibilities for personal transformation.

Performativity accounts for: the socio-material basis of anonymity, revealing how discursive arrangements shape emerging notions of authenticity, which result in a distinct array of disinhibited identity performances i.e. help seekers/wounded healers, and virtuous, confrontational and self-aggrandising self-performances. 
